\title{
Determining rotation cycle and distribution frequency for a vendor-buyer integrated multi-item system considering an external provider and rework
}

\author{
Yuan-Shyi Peter Chiu ${ }^{a}$, Hui-Cun Chen ${ }^{a}$, Huei-Hsin Chang ${ }^{b}$ and Ming-Hon Hwang ${ }^{\text {** }}$
}

${ }^{a}$ Department of Industrial Engineering \& Management, Chaoyang University of Technology, Taichung 413, Taiwan

${ }^{b}$ Department of Financie, Chaoyang University of Technology, Taichung 413, Taiwan

${ }^{c}$ Department of Marketing \& Logistics Management, Chaoyang University of Technology, Taichung 413, Taiwan \begin{abstract}
A B S T R A C T
Transnational corporations, which operate in competitive global marketplaces, have to build the best possible intra-supply chain model for meeting, on time, clients' need for multiple products with the requisite quality. Since fabrication capacity is always limited, the introduction of the external provider option can assist in leveling utilization, smoothing manufacturing schedules, eliminating overtime usage, and shortening the length of the fabrication cycle. Seeking to support intra-supply chain planning, this research aims to provide a concurrent decision on rotation cycle length and delivery frequency for a multi-item vendor-buyer incorporated type of intra-supply chain system with an external provider and rework. First, a model is built to represent this hybrid inventory replenishing problem. Then, renewal reward theory, mathematical derivation, and Hessian matrix equations are utilized to arrive at the expected total cost of the model, as well as the best policies for both cycle time and distribution. Last, the applicability and sensitivity analyses of our results are exhibited by a numerical demonstration. The insights obtained from this study about critical system-related information, such as the individual and joint impacts of the variation in outsourcing and reworking-related features on the system's optimal operating policy and various performance parameters, will offer crucial help to the managerial functions of planning and decision making in firms using this realistic multi-item hybrid intra-supply chain system.
\end{abstract}

\section{Introduction}

Transnational corporations, which operate in competitive global marketplaces, have to build the best possible intra-supply chain model for meeting, on time, clients' need for multiple products with the requisite quality. Planning a batch fabrication on a single machine can not only satisfy customers' demands but also increase utilization. Korgaonker (1979) examined a multi-product flow-shop nature batch fabrication problem with multi-stage structure. Author built a model to integrate fabrication and inventory, and aimed to find concurrent decisions on these products' optimal fabrication cycle and procurement policies of their required materials. Author extended his investigation to multi-facility model by incorporating production concepts of single-item single facility and multi-item batch

* Corresponding author +886 4-23323000 (ext.5205)

E-mail: hwangmh@,cyut.edu.tw (M.-H. Hwang)

2019 Growing Science Ltd.

doi: $10.5267 /$ j.ijiec.2019.4.001 
fabrication. Tamura (1988) considered a multi-product multistage fabrication planning problem, wherein various parts are made and assembled into end items under capacity constraint. Author used the techniques of mixed-integer programming and decomposition approach to formulate the problem and developed an approximate solution method. An extended algorithm for a two-stage fabrication system was also presented. Numerous examples were offered and solved to inspect these algorithms' effectiveness. Güder and Zydiak (1997) proposed a heuristic to explore the order policies for quantity discounts multi-product inventory systems under the constraint of single resource. Through numerical illustrations authors showed that their non-stationary approach could outperform the stationary heuristic. Ueno et al. (2007) addressed a common problem in meeting mass diversity customization needs in the automobile industry. Authors presented a multi-product fabrication planning approach to deal with the problem of mass customization needs under daily production capacity constraint. Stochastic and linear programming techniques were employed to model the problem and sub-problem, respectively. Authors offered an effective and realistic algorithm for resolving the problem. Taleizadeh et al. (2013) examined a multi-item fabrication system with imperfection and under service level and budget constraints, and aimed to minimize overall relevant system cost. Authors proposed a solution approach to find the best operating policy, and offered numerical illustrations and sensitivity analyses to confirm the applicability of their results and provide managerial insights of the problem. Different features of multiproduct fabrication planning and optimization were investigated (Zahorik et al., 1984; Zipkin, 1995; Federgruen et al., 2007; Fergany, 2016; Chiu et al., 2016a,b; Razmi et al., 2016; Zahedi et al., 2016; Rodado et al., 2017; Vujosevic et al., 2017; Chiu et al., 2018a).

Since production capacity is limited, the introduction of the external provider option can assist in leveling utilization, smoothing manufacturing schedules, eliminating overtime usage, and shortening the length of the fabrication cycle. Lee et al. (1997) examined flexible finite-period component selection and loading systems, wherein sets of component types and quantities are chosen in finite periods to meet due dates of demands and operations and facilities are allocated to process these components. Under the condition of demands exceed the machine capacity the option of external provider was used to fully satisfy customers' demands. The objective was to keep subcontracting expenses minimum. Three distinct algorithms namely forward, backward, and capacity approximate, were developed to solve the problems of component selection and loading for each period. Sets of random test problems were generated, calculated, and compared to verify applicability of their proposed algorithms. Berggren and Bengtsson (2004) argued that economic benefit of outsourcing are not always the case as stated in most of the literatures. Authors examined the expenses and competences from the results of implementing outsourcing in two real-life leading companies in Telecom, namely the Ericsson and the Nokia, and revealed amazingly dissimilar strategies for fabrication and outsourcing, which provides support for a serious rethinking of common outsourcing trends. Beladi and Mukherjee (2012) examined the market structure and the hybrid supply system with the aim of exploration of the impacts of market competition and inferences of diverse outsourcers together with in-house fabrication on producer's profitability. Diverse aspects of incorporating outsourcing option into fabrication planning and operating strategy were explored (Cachon \& Harker, 2002; Mendelson \& Parlaktürk, 2008; Mokhtari \& Abadi, 2013; Chakravarty, 2017; Chiu et al., 2017a,b; Fera et al., 2017; Vishwakarma et al., 2017).

The vendor-buyer incorporated type of intra-supply chain system is existent in modern transnational firms, wherein clients' product needs are manufactured in firm's production units, and then multiple shipments of end products are distributed to marketplaces all over the world to satisfy demands. Kohli and Park (1994) examined the single-seller multi-customer transactions coordination problem with the objective of finding the combined ordering policies to minimize total transactional cost. As a result, the optimal price-independent lot sizes were determined. Additionally, authors discovered that the product bundling provides efficient combined orders of all products. Sucky (2004) studied the coordination between buyer's ordering and supplier's fabrication policies within supply-chain systems. Authors proposed a bargaining model based on unequal information on cost structure of buyers, and presented a cost-structure dependent self-choice model for determining the optimal set of agreements. Giri and Roy 
(2013) examined a single-product supplier-client incorporated fabrication-inventory system considering quantity discount and unequal lot-size deliveries. The problem was first modelled and formulated, and mathematical derivations helped find the cost minimization optimal operating policy. Other studies (Banerjee \& Banerjee, 1994; Thomas \& Hackman, 2003; Çömez et al., 2012; Balaji et al., 2016 ; Florea Ionescu et al., 2016; Raj \& Prabha, 2016; Afshar-Nadjafi \& Afshar-Nadjafi, 2017; Buckova et al., 2017; Settanni et al., 2017; Sultana \& Mustafa, 2017; Bolaños et al., 2018) explored diverse features of planning and optimization of the supply-chain systems. In real manufacturing processes, owing to many unanticipated factors fabrication of defective products is unavoidable. These items need to be detected, scrapped or reworked to maintain products at an acceptance quality level. In past decades, many studies (Groenevelt et al., 1992; Nourelfath, 2011; Kaylani et al., 2016; Regti et al., 2017; Saari \& Odelius, 2018) explored imperfect fabrication systems considering various dissimilar features, such as defects, rework of defects, facility breakdowns, etc. Seeking to support intra-supply chain planning, this study finds a concurrent decision on rotation cycle and distribution frequency for a multi-item vendor-buyer incorporated system with an external provider and rework. Prior research paid little attention to the combined impacts of external provider and rework on the multi-item intra-supply chains decision, this work intends to fill this research gap.

\section{Notation and problem statement}

This study determines rotation cycle time and distribution policy for a vendor-buyer integrated multiitem system considering an outside provider and rework of nonconforming products. Nomenclature and problem statement are provided as follows:

\subsection{Nomenclature}

$\pi_{i}=$ outsourcing portion of the lot-size of product $i$,

$C_{\mathrm{i}}=$ unit in-house production cost of product $i$,

$C_{\pi \mathrm{i}}=$ unit outsourcing cost for product $i$,

$\beta_{2 i}=$ connecting parameter between $C_{\pi \mathrm{i}}$ and $C_{\mathrm{i}}$, where $C_{\pi i}=\left(1+\beta_{2 i}\right) C_{i}$ and assuming $\beta_{2}>0$,

$C_{\mathrm{Ri}}=$ unit rework cost for product $i$,

$C_{\mathrm{Ti}}=$ unit distribution cost for product $i$,

$D_{\mathrm{i}}=$ fixed quantity for product $i$ per shipment,

$d_{1 \mathrm{i}}=$ production rate of nonconforming product $i$,

$h_{1 \mathrm{i}}=$ unit holding cost for reworked product $i$,

$h_{2 \mathrm{i}}=$ unit holding cost for product $i$ in the buyer side,

$h_{\mathrm{i}}=$ unit holding cost for product $i$,

$H_{\mathrm{i}}=$ maximum on-hand level of finished item $i$ at the time when outsourced items are received,

$H_{1 \mathrm{i}}=$ on-hand inventory of end product $i$ when uptime finishes,

$H_{2 \mathrm{i}}=$ on-hand inventory of finished product $i$ when rework time finsihes,

$I_{\mathrm{i}}=$ stock level of product $i$ when demand in $t_{\mathrm{ni \pi}}$ is met,

$I(t)_{\mathrm{i}}=$ inventory level of end products at time $t$,

$I_{\mathrm{D}}(t)_{\mathrm{i}}=$ inventory level of nonconforming products at time $t$,

$I_{\mathrm{c}}(t)_{\mathrm{i}}=$ inventory level of end product $i$ in the buyer side at time $t$,

$K_{\mathrm{i}}=$ in-house setup cost for product $i$,

$K_{\pi \mathrm{i}}=$ fixed outsourcing cost for product $i$,

$\beta_{1 i}=$ connecting parameter between $K_{\pi \mathrm{i}}$ and $K_{\mathrm{i}}$, where $K_{\pi i}=\left(1+\beta_{1 i}\right) K_{i}$, and reasonably assuming that $\left(-1<\beta_{1 i}<0\right)$,

$K_{1 i}=$ fixed transportation cost for product $i$,

$L=$ number of end products,

$n=$ number of deliveries in a cycle - another decision variable,

$P_{1 i}=$ annual production rate of product $i$,

$P_{2 i}=$ annual reworking rate of product $i$, 
$\lambda_{i}=$ demand rate per year for product $i$,

$Q_{\mathrm{i}}=$ lot size in a cycle for product $i$,

$t_{1 \text { i }}=$ uptime for product $i$,

$t_{2 \mathrm{i} \pi}=$ rework time for product $i$,

$t_{3 i \pi}=$ transportation time for product $i$,

$t_{\mathrm{ni} \pi}=$ fixed period of time between two succeeding shipments in $t_{3 i \pi}$,

$T_{\pi}=$ rotation cycle time - decision variable;

$t_{1 \mathrm{i}}=$ uptime of product $i$ in a system without outsourcer,

$t_{2 \mathrm{i}}=$ rework time of product $i$ in the proposed system without outsourcer,

$t_{3 \mathrm{i}}=$ transportation time for product $i$ in the proposed system without outsourcer,

$T=$ cycle time in the proposed system without outsourcer,

$T C\left(T_{\pi}, n\right)=$ total system cost in a cycle,

$x_{i}=$ a portion of nonconforming items during fabrication of product $i$-random variable with a known probability distribution,

$\mathrm{E}\left[x_{i}\right]=$ the expected value $x_{i}$,

$\mathrm{E}\left[\operatorname{TCU}\left(T_{\pi}, n\right)\right]=$ expected system cost per unit time,

$\bar{\pi}=$ the average of $\pi_{i}$,

$\bar{x}=$ the average of $x_{i}$,

$\overline{C_{\mathrm{R}}}=$ the average of $C_{\mathrm{R} i}$,

$\bar{C}=$ the average of $C_{i}$,

$\overline{\beta_{1}}=$ the average of $\beta_{1 i}$,

$\overline{\beta_{2}}=$ the average of $\beta_{2 i}$.

\subsection{Problem statement}

A hybrid multiproduct vendor-buyer integrated system with an outside provider and rework of the nonconforming products is described as follows. $L$ different end products with annual demand are to be refilled by a hybrid batch-based system, where a $\pi_{i}$ portion of lot-size $Q_{i}$ of each product $i$ is outsourced $(i=1,2, \ldots, L)$ and the outsourcer ensures the product quality of all outsourced items and their delivery time (i.e., prior to the system transportation time $t_{3 i \pi}$ for each product $i$ ). Consequently, different fixed and unit costs (i.e., $K_{\pi \mathrm{i}}$ and $C_{\pi \mathrm{i}}$ ) are associated with outsourced items (Fig. 1).

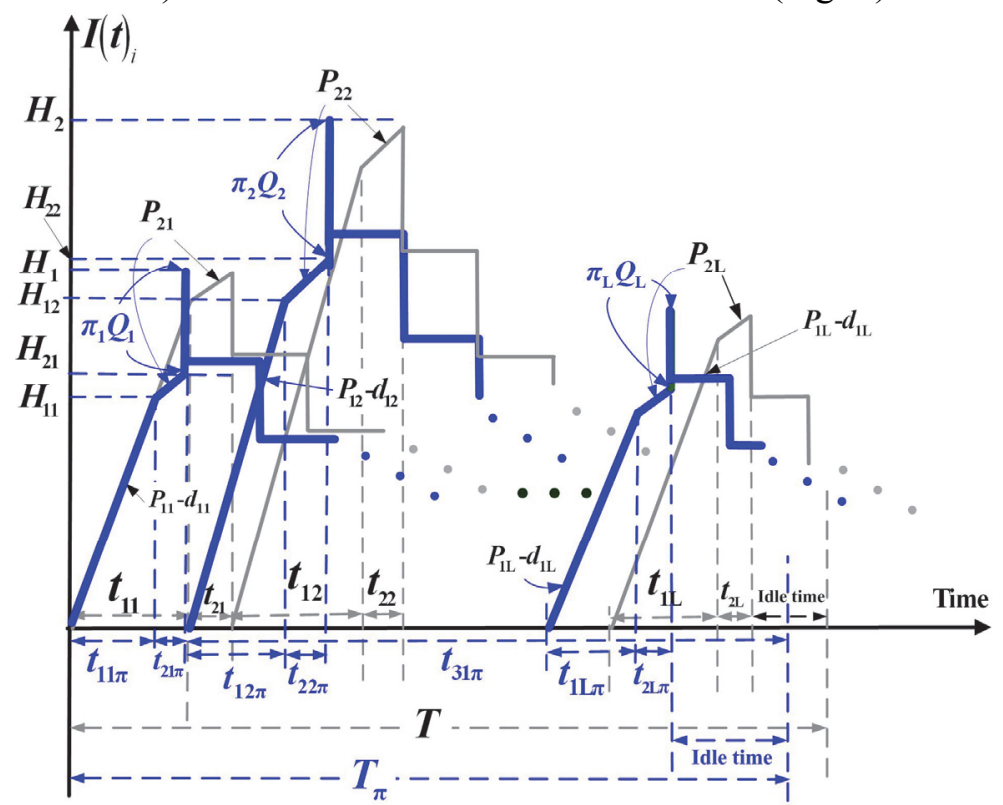

Fig. 1. Status of on-hand inventory for each end product in the proposed hybrid refilling system with outside provider, rework, and multi-delivery plan 
The other $\left(1-\pi_{i}\right)$ portion of lot-size $Q_{i}$ of each product $i$ is produced in-house at a rate of $P_{1 i}$. But, for each product $i$ an $x_{i}$ proportion of nonconforming items are produced randomly during in-house production processes at a rate of $d_{1 i}$ (so, $d_{1 i}=x_{i} P_{1 i}$ ). Further, we assume that all nonconforming items are repairable with extra unit cost $C_{\mathrm{R} i}$, via a rework process immediately after fabrication of each product $i$, at a rate of $P_{2 i}$ in the same refilling cycle (Fig. 1). The stock status of nonconforming items of each product $i$ in the proposed hybrid refilling system is exhibited in Fig. 2. No shortages are permissible, so the inventory accumulation rate during uptime must be greater than zero, that is $\left(P_{1 i}-d_{1 i}-\lambda_{i}\right)>0$. Upon completion of the reworking, outsourced items are received in time as planned, so the stock level arrives $H_{i}$ prior to the beginning of a multi-delivery plan. Then, fixed-amount $n$ installments of the finished lot of product $i$ are transported to buyer at fixed time intervals of $t_{\text {nix }}$ (see Fig. 1 and Fig. 3). The stock status of product $i$ in the buyer's side is shown in Fig. 4.

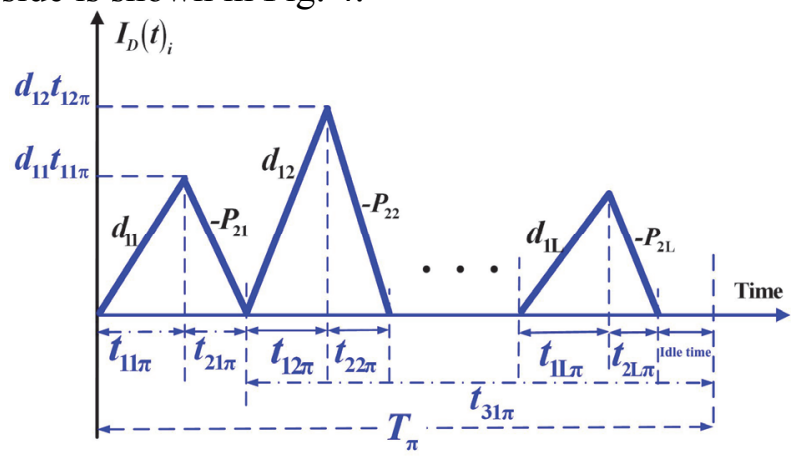

Fig. 2. Status of on-hand nonconforming items of each product $i$ in the proposed hybrid refilling system

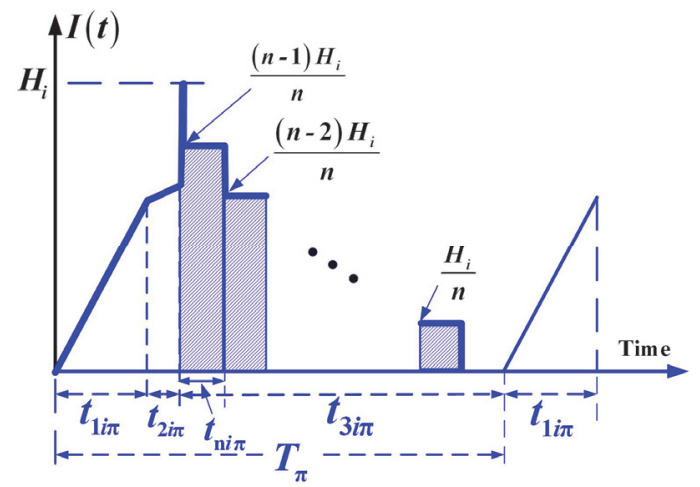

Fig. 3. Status of on-hand finished items of product $i$ in $t_{3 i \pi}$ in the proposed hybrid refilling system

\section{Mathematical modeling and solution}

From problem statement and through observing the aforementioned figures, the following equations can be clearly obtained (for $i=1,2, \ldots, L$ ):

$$
\begin{aligned}
& H_{1 i}=\left(P_{1 i}-d_{1 i}\right) t_{1 i \pi} \\
& H_{2 i}=H_{1 i}+P_{2 i} t_{2 i \pi} \\
& H_{i}=H_{2 i}+\pi_{i} Q_{i}=\lambda_{i} \cdot T_{\pi} \\
& t_{1 i \pi}=\frac{\left(1-\pi_{i}\right) Q_{i}}{P_{1 i}}=\frac{H_{1 i}}{P_{1 i}-d_{1 i}}
\end{aligned}
$$




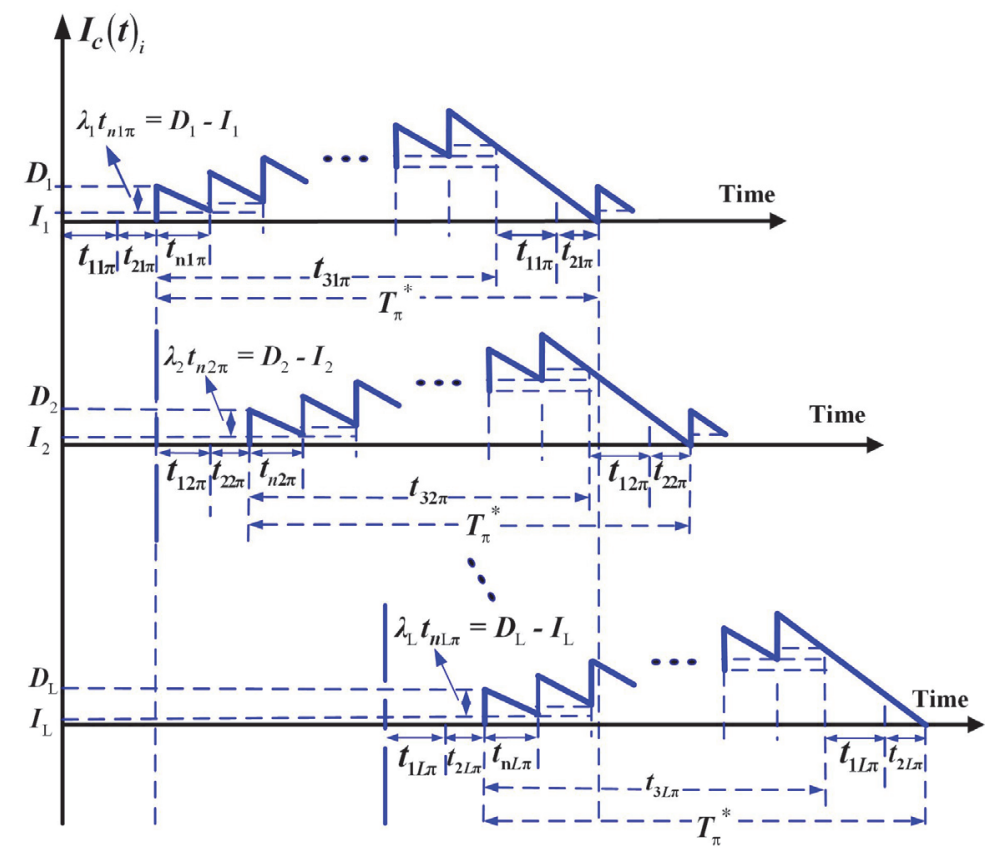

Fig. 4. The stock status of product $i$ in the buyer's side of the proposed hybrid refilling system

$$
\begin{aligned}
& t_{2 i \pi}=\frac{x_{i}\left[\left(1-\pi_{i}\right) Q_{i}\right]}{P_{2 i}} \\
& t_{3 i \pi}=T_{\pi}-\left(t_{1 i \pi}+t_{2 i \pi}\right)=n \cdot t_{\mathrm{n} i \pi} \\
& T_{\pi}=t_{1 i \pi}+t_{2 i \pi}+t_{3 i \pi} \\
& Q_{i}=\lambda_{i} T_{\pi} \\
& d_{1 i} t_{1 i \pi}=x_{i} P_{1 i} t_{1 i \pi}=x_{i}\left[\left(1-\pi_{i}\right) Q_{i}\right] .
\end{aligned}
$$

During the transportation time $t_{3 i \pi}$ (Fig. 3) the total inventories of product $i$ are as follows (see Appendix A for detailed calculation):

$$
\left(\frac{1}{n^{2}}\right)\left(\sum_{i=1}^{n-1} i\right) H_{i}\left(t_{3 i \pi}\right)=\left(\frac{1}{n^{2}}\right)\left[\frac{n(n-1)}{2}\right] H_{i}\left(t_{3 i \pi}\right)=\left(\frac{n-1}{2 n}\right) H_{i}\left(t_{3 i \pi}\right) .
$$

In the buyer's side (Fig. 4), since $n$ fixed-amount shipments are distributed at a fixed time period $t_{\text {ni }}$, so one can clearly identify Eq. (11) to Eq. (13).

$$
\begin{aligned}
& D_{i}=\frac{H_{i}}{n} \\
& t_{\mathrm{n} i \pi}=\frac{t_{3 i \pi}}{n} \\
& I_{i}=D_{i}-\lambda_{i} t_{\mathrm{n} i \pi}
\end{aligned}
$$

Total inventories in the buyer's side are

$$
\frac{1}{2}\left[\frac{H_{i} t_{3 i \pi}}{n}+T_{\pi}\left(H_{i}-\lambda_{i} t_{3 i \pi}\right)\right]
$$


$T C\left(T_{\pi}, n\right)$ - the total system cost per cycle, comprises outsourcing costs (both fixed and variable), inhouse setup and variable manufacturing and rework costs, transportation costs (both fixed and variable), holding cost including finished, nonconforming, and reworked items in the entire refilling cycle, and buyer's holding costs.

$$
T C\left(T_{\pi}, n\right)=\sum_{i=1}^{L}\left\{\begin{array}{l}
K_{\pi i}+C_{\pi i} \pi_{i} Q_{i}+K_{i}+C_{i}\left(1-\pi_{i}\right) Q_{i}+C_{\mathrm{Ri}} x_{i}\left[\left(1-\pi_{i}\right) Q_{i}\right]+n K_{1 i}+C_{T i} Q_{i} \\
+h_{i}\left[\frac{H_{1 i}+d_{1 i} t_{1 i \pi}}{2}\left(t_{1 i \pi}\right)+\frac{H_{1 i}+H_{2 i}}{2}\left(t_{2 i \pi}\right)+\left(\frac{n-1}{2 n}\right) H_{i}\left(t_{3 i \pi}\right)\right] \\
+h_{1 i} \frac{P_{2 i} t_{2 i \pi}}{2}\left(t_{2 i \pi}\right)+\frac{h_{2 i}}{2}\left[\frac{H_{i} t_{3 i \pi}}{n}+T_{\pi}\left(H_{i}-\lambda_{i} t_{3 i \pi}\right)\right]
\end{array}\right\} .
$$

Since $K_{\pi i}=\left(1+\beta_{1 i}\right) K_{i}$ and $C_{\pi i}=\left(1+\beta_{2 i}\right) C_{i}$, by substituting them in Eq. (15), employing the expected values $\mathrm{E}\left[x_{i}\right]$ to deal with randomness of $x_{i}$, replacing Eqs. (1) to (14) in Eq. (15), and with additional efforts in derivations the following $\mathrm{E}\left[\operatorname{TCU}\left(T_{\pi}, n\right)\right]$ can be derived:

$$
\begin{aligned}
E\left[T C U\left(T_{\pi}, n\right)\right] & =\frac{E\left[T C\left(T_{\pi}, n\right)\right]}{E\left[T_{\pi}\right]}=\sum_{i=1}^{L}\left\{\frac{K_{i}\left(1+\beta_{1 i}\right)}{T_{\pi}}+\frac{K_{i}}{T_{\pi}}+\frac{n K_{1 i}}{T_{\pi}}+C_{T i} \lambda_{i}\right\} \\
& +\sum_{i=1}^{L} \lambda_{i}\left\{\begin{array}{l}
\left(1+\beta_{2 i}\right) C_{i} \pi_{i}+C_{i}\left(1-\pi_{i}\right)+C_{\mathrm{Ri}} E\left[x_{i}\right]\left(1-\pi_{i}\right)+\frac{h_{2 i} T_{\pi} E_{i}}{2}+\frac{h_{i} T_{\pi} E_{3 i}}{2} \\
+\frac{T_{\pi}\left(h_{2 i}-h_{i}\right)}{2}\left(\frac{1}{n}\right)\left(1-E_{i}\right)+\frac{\lambda_{i} T_{\pi} E\left[x_{i}\right]^{2}\left(1-\pi_{i}\right)^{2}\left(h_{1 i}-h_{i}\right)}{2 P_{2 i}}
\end{array}\right\},
\end{aligned}
$$

where $E_{i}=\frac{\lambda_{i}\left(1-\pi_{i}\right)}{P_{1 i}}+\frac{\lambda_{i} E\left[x_{i}\right]\left(1-\pi_{i}\right)}{P_{2 i}} ; E_{3 i}=\left[1-\frac{\lambda_{i}\left(1-\pi_{i}\right) \pi_{i}}{P_{1 i}}+\frac{\lambda_{i} E\left[x_{i}\right]\left(1-\pi_{i}\right)}{P_{2 i}}\left(1-2 \pi_{i}\right)\right]$

\subsection{Convexity and optimality}

This subsection first uses Hessian matrix equations (Rardin, 1998) to prove convexity of $\mathrm{E}\left[T C U\left(T_{\pi}, n\right)\right]$, the partial derivatives are expressed below:

$$
\begin{aligned}
& \frac{\partial^{2} E\left[\operatorname{TCU}\left(T_{\pi}, n\right)\right]}{\partial T_{\pi}^{2}}=\sum_{i=1}^{L} 2\left[\frac{K_{i}\left(1+\beta_{1 i}\right)+\left(K_{i}+n K_{1 i}\right)}{T_{\pi}^{3}}\right] \\
& \frac{\partial^{2} E\left[T C U\left(T_{\pi}, n\right)\right]}{\partial n^{2}}=\sum_{i=1}^{L} \lambda_{i}\left[T_{\pi}\left(h_{2 i}-h_{i}\right)\left(\frac{1}{n^{3}}\right)\left(1-E_{i}\right)\right] \\
& \frac{\partial E\left[T C U\left(T_{\pi}, n\right)\right]}{\partial T_{\pi} \partial n}=\sum_{i=1}^{L}\left[\frac{-K_{1 i}}{T_{\pi}^{2}}\right]+\sum_{i=1}^{L} \lambda_{i}\left[\frac{-\left(h_{2 i}-h_{i}\right)}{2}\left(\frac{1}{n^{2}}\right)\left(1-E_{i}\right)\right]
\end{aligned}
$$

From Eq. (17) to Eq. (19) and with additional derivation, we obtain Eq. (20).

$$
\left[\begin{array}{ll}
T_{\pi} & n
\end{array}\right] \cdot\left(\begin{array}{ll}
\frac{\partial^{2} E\left[T C U\left(T_{\pi}, n\right)\right]}{\partial T_{\pi}^{2}} & \frac{\partial^{2} E\left[T C U\left(T_{\pi}, n\right)\right]}{\partial T_{\pi} \partial n} \\
\frac{\partial^{2} E\left[T C U\left(T_{\pi}, n\right)\right]}{\partial T_{\pi} \partial n} & \left.\frac{\partial^{2} E\left[T C U\left(T_{\pi}, n\right)\right]}{\partial n^{2}}\right) \cdot\left[\begin{array}{c}
T_{\pi} \\
n
\end{array}\right]=2 \sum_{i=1}^{L}\left[\frac{K_{i}\left(1+\beta_{1 i}\right)+K_{i}}{T_{\pi}}\right]>0 .
\end{array}\right.
$$

Since $K_{i}, T_{\pi}$, and $\left(1+\beta_{1 i}\right)$ are all positive, so Eq. (20) is positive. Hence, $\mathrm{E}\left[T C U\left(T_{\pi}, n\right)\right]$ is strictly convex for all values of $n$ and $T_{\pi}$ other than zero, so a minimum value of $\mathrm{E}\left[\operatorname{TCU}\left(T_{\pi}, n\right)\right]$ exists. To find the optimal $T_{\pi}{ }^{*}$ and $n *$ simultaneously, one can first set the following first derivatives of $\mathrm{E}\left[\operatorname{TCU}\left(T_{\pi}, n\right)\right]$ with respect 
to $n$ and $T_{\pi}$ equal to zero, then resolve the linear system of Eq. (21) and Eq. (22).

$$
\begin{aligned}
\frac{\partial E\left[T C U\left(T_{\pi}, n\right)\right]}{\partial n} & =\sum_{i=1}^{L}\left[\frac{K_{1 i}}{T_{\pi}}\right]-\sum_{i=1}^{L} \lambda_{i}\left[\frac{T_{\pi}\left(h_{2 i}-h_{i}\right)}{2}\left(\frac{1}{n^{2}}\right)\left(1-E_{i}\right)\right]=0 \\
\frac{\partial E\left[T C U\left(T_{\pi}, n\right)\right]}{\partial T_{\pi}}= & =\sum_{i=1}^{L}\left\{\frac{-K_{i}\left(1+\beta_{1 i}\right)}{T_{\pi}^{2}}-\frac{K_{i}}{T_{\pi}^{2}}-\frac{n K_{1 i}}{T_{\pi}^{2}}\right\} \\
& +\sum_{i=1}^{L} \lambda_{i}\left\{\frac{h_{2 i} \lambda_{i} E_{i}}{2}+\frac{h_{i}}{2} E_{3 i}+\frac{\left(h_{2 i}-h_{i}\right)}{2}\left(\frac{1}{n}\right)\left(1-E_{i}\right)+\frac{\lambda_{i} E\left[x_{i}\right]^{2}\left(1-\pi_{i}\right)^{2}}{2 P_{2 i}}\left(h_{1 i}-h_{i}\right)\right\}=0
\end{aligned}
$$

With extra derivations, the following optimal policy of cycle time and distribution frequency $\left(T_{\pi}^{*}, n^{*}\right)$ is found:

$$
T_{\pi}^{*}=\sqrt{\frac{2 \sum_{i=1}^{L}\left[K_{i}\left(2+\beta_{1 i}\right)+n K_{1 i}\right]}{\sum_{i=1}^{L} \lambda_{i}\left[\frac{\lambda_{i} E\left[x_{i}\right]^{2}\left(1-\pi_{i}\right)^{2}}{P_{2 i}}\left(h_{1 i}-h_{i}\right)+h_{2 i} E_{i}+\left(h_{2 i}-h_{i}\right)\left(\frac{1}{n}\right)\left(1-E_{i}\right)+h_{i} E_{3 i}\right]}},
$$

and

$$
n^{*}=\sqrt{\frac{\sum_{i=1}^{L}\left[K_{i}\left(2+\beta_{1 i}\right)\right] \cdot \sum_{i=1}^{L}\left[\lambda_{i}\left(h_{2 i}-h_{i}\right)\left(1-E_{i}\right)\right]}{\sum_{i=1}^{L}\left(K_{1 i}\right) \cdot \sum_{i=1}^{L} \lambda_{i}\left[\frac{\lambda_{i} E\left[x_{i}\right]^{2}\left(1-\pi_{i}\right)^{2}}{P_{2 i}}\left(h_{1 i}-h_{i}\right)+h_{2 i} E_{i}+h_{i} E_{3 i}\right]}},
$$

where $E_{i}=\frac{\lambda_{i}\left(1-\pi_{i}\right)}{P_{1 i}}+\frac{\lambda_{i} E\left[x_{i}\right]\left(1-\pi_{i}\right)}{P_{2 i}} ; E_{3 i}=\left[1-\frac{\lambda_{i}\left(1-\pi_{i}\right) \pi_{i}}{P_{1 i}}+\frac{\lambda_{i} E\left[x_{i}\right]\left(1-\pi_{i}\right)}{P_{2 i}}\left(1-2 \pi_{i}\right)\right]$

\subsection{Impact of setup times and prerequisite of machine capacity}

\subsubsection{Impact of setup times on cycle length}

When the summation of setup times $S_{i}$ of product $i_{i}$ is longer than the idle time of the system, then it can no longer be ignored, the rotation cycle length must be large enough to contain the sum of setup, regular fabrication, and rework times for $L$ products as follows:

$$
T_{\pi}>\sum_{i=1}^{L}\left[S_{i}+\left(\frac{\left(1-\pi_{i}\right) Q_{i}}{P_{1 i}}\right)+\left(\frac{\left(1-\pi_{i}\right) Q_{i} E\left[x_{i}\right]}{P_{2 i}}\right)\right],
$$

or, $T_{\pi}$ must be greater than $T_{\min }$ as follows (for detailed derivations please see Appendix B):

$$
T_{\pi}>\frac{\sum_{i=1}^{L}\left(S_{i}\right)}{1-\sum_{i=1}^{L}\left[\left(\frac{\left(1-\pi_{i}\right) \lambda_{i}}{P_{1 i}}\right)+\left(\frac{\left(1-\pi_{i}\right) \lambda_{i} E\left[x_{i}\right]}{P_{2 i}}\right)\right]}=T_{\min }
$$

In summary, if the sum of setup times becomes noteworthy to cycle length, one should choose the maximum of $T_{\pi}^{*}$ (Eq. (23)) or $T_{\min }$ (Eq. (26)) as mentioned by Nahmias (2009). 


\subsubsection{Prerequisite of machine capacity}

While planning the batch fabrication of $L$ products, one must ensure that there is sufficient capacity to do so. Meaning the prerequisite condition as expressed in Eq. (27) must be true:

$$
\sum_{i=1}^{L}\left[\left(\frac{\left(1-\pi_{i}\right) \lambda_{i}}{P_{1 i}}\right)+\left(\frac{\left(1-\pi_{i}\right) \lambda_{i} E\left[x_{i}\right]}{P_{2 i}}\right)\right]<1
$$

\section{Example with analyses}

Assume that the following values associated with parameters of the proposed vendor-buyer integrated multi-item system with an outside provider and rework (see Table 1):

\section{Table 1}

Assumption of values of parameters in the proposed vendor-buyer integrated multi-item system

\begin{tabular}{|c|c|c|c|c|c|c|c|c|c|c|c|c|c|c|c|c|c|}
\hline Item \# & $P_{1 i}$ & $\lambda_{i}$ & $C_{i}$ & $h_{i}$ & $K_{i}$ & $x_{i}$ & $P_{2 i}$ & $C_{\mathrm{R} i}$ & $h_{1 i}$ & $\pi_{i}$ & $\beta_{1 i}$ & $\beta_{2 i}$ & $K_{\pi i}$ & $C_{\pi i}$ & $K_{1 i}$ & $C_{\mathrm{T} i}$ & $h_{2 i}$ \\
\hline 1 & 58000 & 3000 & 80 & 10 & 10000 & $5 \%$ & 2900 & 50 & 30 & 0.4 & -0.60 & 0.40 & 4000 & 112.0 & 2300 & 0.1 & 50 \\
\hline 2 & 59000 & 3200 & 90 & 15 & 11000 & $10 \%$ & 2950 & 55 & 35 & 0.4 & -0.65 & 0.35 & 3850 & 121.5 & 2400 & 0.2 & 55 \\
\hline 3 & 60000 & 3400 & 100 & 20 & 12000 & $15 \%$ & 3000 & 60 & 40 & 0.4 & -0.70 & 0.30 & 3600 & 130.0 & 2500 & 0.3 & 60 \\
\hline 4 & 61000 & 3600 & 110 & 25 & 13000 & $20 \%$ & 3050 & 65 & 45 & 0.4 & -0.75 & 0.25 & 3250 & 137.5 & 2600 & 0.4 & 65 \\
\hline 5 & 62000 & 3800 & 120 & 30 & 14000 & $25 \%$ & 3100 & 70 & 50 & 0.4 & -0.80 & 0.20 & 2800 & 144.0 & 2700 & 0.5 & 70 \\
\hline
\end{tabular}

Firstly, by applying Eqs. (23), (24), and (16), we find that $n^{*}=3, T_{\pi}^{*}=0.5939, E\left[T C U\left(T_{\pi}^{*}, n^{*}\right)\right]=$ $\$ 2,358,872$ (see Table C-1 in Appendix C; for $\bar{\pi}=0.4$ ). Looking into the rework feature of our propose model, an investigative result of the effect of deviations in ratio of average unit rework cost over average unit production $\operatorname{cost}\left(\overline{C_{\mathrm{R}}} / \bar{C}\right)$ on $E\left[T C U\left(T_{\pi}^{*}, n^{*}\right)\right]$ is displayed in Fig. 5. It indicates that $E\left[T C U\left(T_{\pi}^{*}, n^{*}\right)\right]$ increases, as the $\left(\overline{C_{\mathrm{R}}} / \bar{C}\right)$ ratio goes up; and at $\overline{C_{\mathrm{R}}} / \bar{C}=0.6$ (as assumed in our example), $E\left[T C U\left(T_{\pi}^{*}, n^{*}\right)\right]$ $=\$ 2,358,872$.

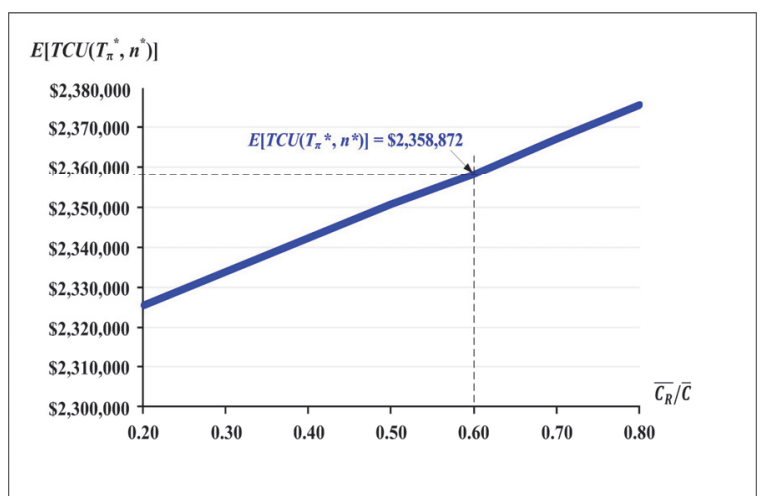

Fig. 5. Effect of deviations in ratio of unit rework cost $\left(\overline{C_{\mathrm{R}}} / \bar{C}\right)$ on $E\left[T C U\left(T_{\pi}^{*}, n^{*}\right)\right]$

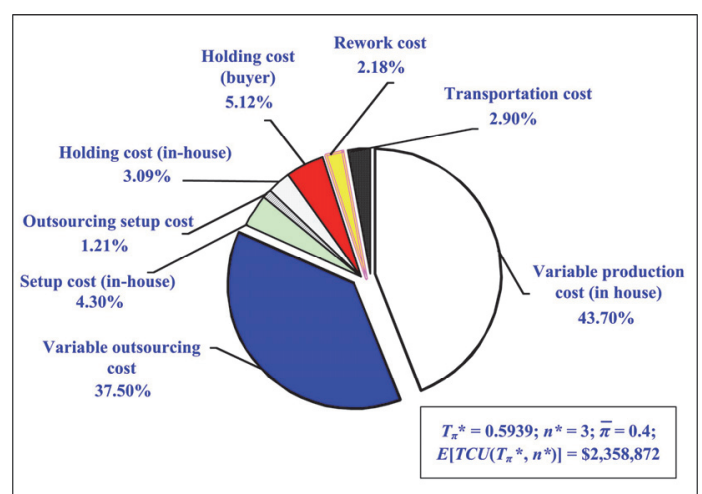

Fig. 6. Analytical outcomes of major contributors of $E\left[T C U\left(T_{\pi}^{*}, n^{*}\right)\right]$

Detailed cost analyses on major contributors in $E\left[T C U\left(T_{\pi}^{*}, n^{*}\right)\right]$ are conducted and outcomes are exhibited in Fig. 6. It points out that the outsourcing setup cost is $1.21 \%$ and variable outsourcing cost is $37.50 \%$, hence, total outsourcing related cost amounts to $38.71 \%$ (for $\bar{\pi}=0.4$; see Table C-1). The quality (rework) cost of the proposed system is $\$ 51,425$ (Table C-1), i.e., $2.18 \%$ of $E\left[T C U\left(T_{\pi}^{*}, n^{*}\right)\right]$; and other in-house related cost is $51.09 \%$ (see Table C- 1 ), which including setup cost $4.30 \%$, holding cost 3.09\%, and variable production cost $43.70 \%$. Fig. 7 illustrates the exploratory result of the impact of variations in $\bar{\pi}$ on total cost for each end item. It indicates that the total cost for each end item raises as $\bar{\pi}$ goes up, because the unit outsourcing cost is greater than unit in-house production cost. 


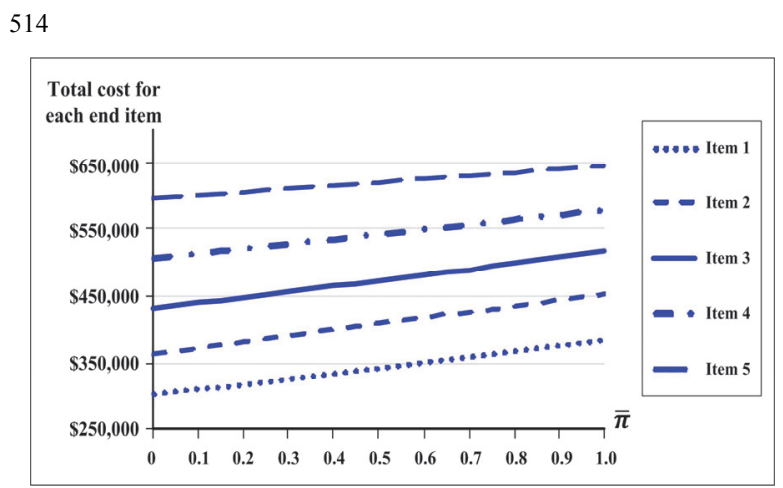

Fig. 7. Impact of variations in $\bar{\pi}$ on total cost for each end item

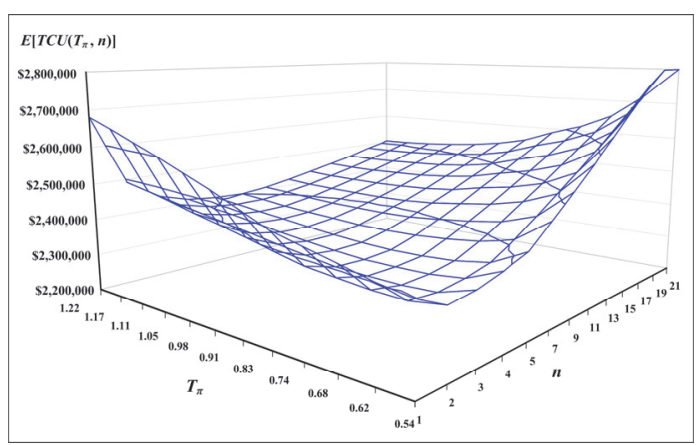

Fig. 8. Joint effects of deviations in $T_{\pi}$ and $n$ on $\mathrm{E}\left[\operatorname{TCU}\left(T_{\pi}^{*}, n^{*}\right)\right]$

Extra analytical result of joint effects of deviations in decision variables $T_{\pi}$ and $n$ on $\mathrm{E}\left[T C U\left(T_{\pi}^{*}, n^{*}\right)\right]$ is displayed in Fig. 8. It shows that $\mathrm{E}\left[T C U\left(T_{\pi}^{*}, n^{*}\right)\right]$ begins to boost up considerably, as both $T_{\pi}$ and $n$ deviate from their optimal points. Fig. 9 demonstrates the impact of differences in average outsourcing ratio $\bar{\pi}$ on total utilization for the proposed vendor-buyer integrated multi-item system with outside provider and rework. It is noted that total utilization decreases severely, as $\bar{\pi}$ raises; and utilization drops to 0.4316 at $\bar{\pi}=0.4$ (from 0.7193 when outsourcing plan is not implemented, i.e., $\bar{\pi}=0$ (Table C-2); however, such a decline in utilization is at the expense of $7.65 \%$ increase in $\mathrm{E}\left[\operatorname{TCU}\left(T_{\pi}^{*}, n^{*}\right)\right]$, see Tables $\mathrm{C}-1$ and $\mathrm{C}-2$ ). Additionally, the actual production uptime, rework time, and machine idle time (in year) per cycle are also exposed by the proposed study (refer to Table C-2).

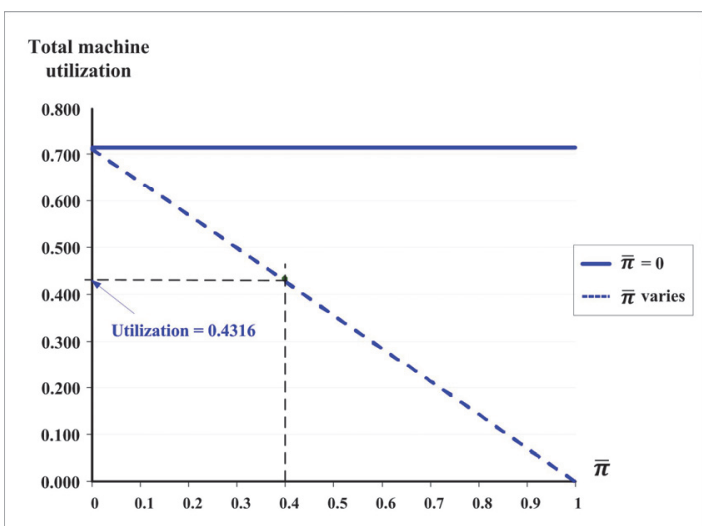

Fig. 9. Impact of differences in average outsourcing ratio $\bar{\pi}$ on total utilization

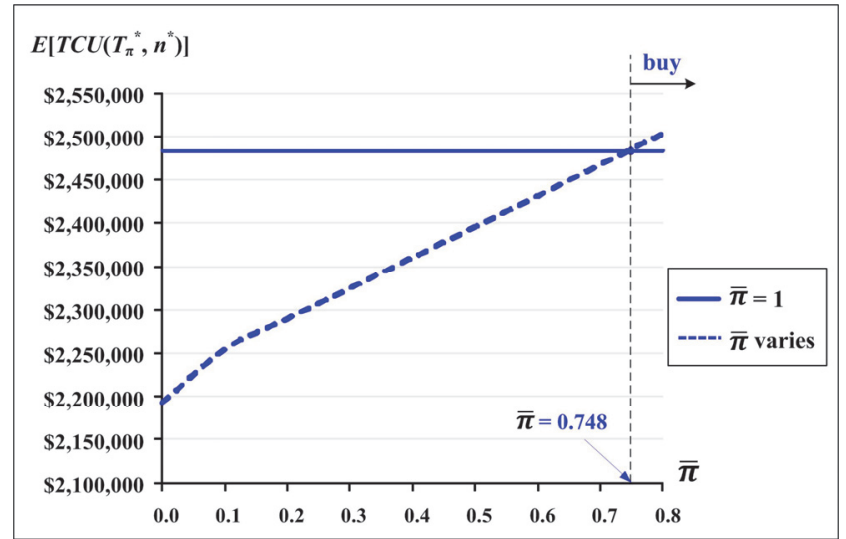

Fig. 10. Variations in $\bar{\pi}$ effect on $E\left[T C U\left(T_{\pi}^{*}, n^{*}\right)\right]$ for judging make-or-buy choice

Further research on the outsourcing feature of our propose model, discovers a critical ratio of $\bar{\pi}=0.748$, as presented in Fig. 10. It shows that $\mathrm{E}\left[\operatorname{TCU}\left(T_{\pi}{ }^{*}, n^{*}\right)\right]$ increases significantly, as $\bar{\pi}$ goes up. It particularly points out that if $\bar{\pi}>0.748$, the 'buy' decision (i.e., a $100 \%$ outsourcing policy) is recommended (see also Table C-2). Extra investigative result on the joint impacts of changes in average defective rate $\bar{x}$ and average outsourcing setup cost connecting parameter $\bar{\beta}_{1}$ on optimal cycle time $T_{\pi}{ }^{*}$ is depicted in Fig. 11. It points out that $T_{\pi}{ }^{*}$ slightly declines, as $\bar{\beta}_{1}$ raises; and $T_{\pi}{ }^{*}$ radically decreases, as average defective rate $\bar{x}$ increases. Especially, it shows a big drop on $T_{\pi}^{*}$ when $\bar{x}$ falls between 0.4 and 0.5 , which is merely due to the decision variable $n^{*}$ changing from 3 to 4 . Additional analytical outcome on the effect of differences in $\bar{\pi}$ on various system cost contributors is illustrated in Fig. 12. It specifies that as $\bar{\pi}$ raises, in-house variable fabrication cost reduces drastically, but conversely, the variable outsourcing cost for outside provider boosts up hugely. It also confirms that at $\bar{\pi}=0.4$, optimal $\operatorname{cost} E\left[T C U\left(T_{\pi}^{*}\right.\right.$, $\left.\left.n^{*}\right)\right]=\$ 2,358,872$. 


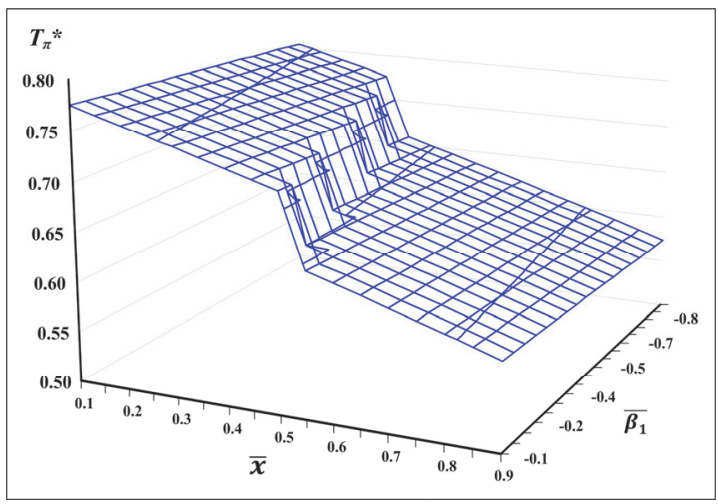

Fig. 11. Joint impacts of changes in $\bar{x}$ and $\overline{\beta_{1}}$ on optimal cycle time $T_{\pi}{ }^{*}$

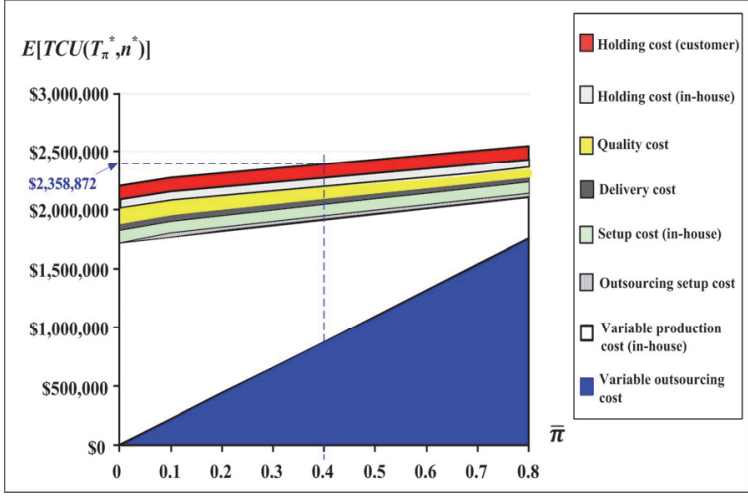

Fig. 12. Effect of differences in $\bar{\pi}$ on various system cost contributors

Lastly, Fig. 13 exhibits joint impacts of changes in average outsourcing unit cost connecting parameter $\overline{\beta_{2}}$ and average outsourcing ratio $\bar{\pi}$ on optimal system $\operatorname{cost} E\left[T C U\left(T_{\pi}^{*}, n^{*}\right)\right]$. It indicates that $E\left[T C U\left(T_{\pi}^{*}\right.\right.$, $\left.\left.n^{*}\right)\right]$ goes up considerably, as both $\overline{\beta_{2}}$ and $\bar{\pi}$ raise. Particularly, $E\left[T C U\left(T_{\pi}^{*}, n^{*}\right)\right]$ boosts up sharply, when $\overline{\beta_{2}}$ and $\bar{\pi}$ are both greater than 0.5 .

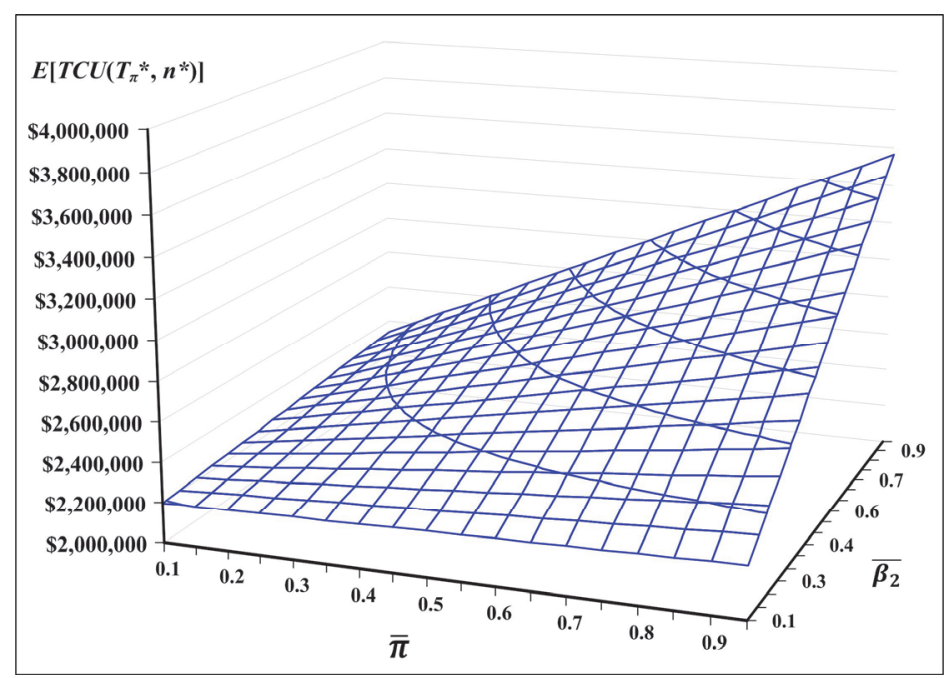

Fig. 13. Joint impacts of changes in $\bar{\pi}$ and $\overline{\beta_{2}}$ on $E\left[T C U\left(T_{\pi}^{*}, n^{*}\right)\right]$

\section{Concluding remarks}

This study has accomplished the concurrent derivation of the rotation cycle and distribution frequency for a multi-item vendor-buyer incorporated type of intra-supply chain system by considering an external provider and rework. First, a model was built to represent this hybrid inventory replenishing problem. Then, renewal reward theory, mathematical derivation, and Hessian matrix equations were used to arrive at the expected total cost of the model, as well as the optimal policies for both cycle time and distribution. Last, the applicability and sensitivity analyses of the research results were exhibited through a numerical demonstration. The insights obtained from this study about critical system-related information, such as the individual and joint impacts of the variation in outsourcing- and reworking-related features on the system's optimal operating policy and various performance parameters (refer to section 4), will offer crucial help to the managerial functions of planning and decision making in firms using this realistic multi-item hybrid intra-supply chain system. Future research could focus on the effect of demand uncertainty on this specific problem. 


\section{Acknowledgements}

Authors truly express gratitude to Ministry of Science and Technology of Taiwan for its sponsorship of this research (fund \#: MOST 105-2410-H-324-003)

\section{Appendix - A}

The detailed calculations of vendor's total inventories (i.e., Eq. (10)) during transportation time $t_{3 i \pi}$ are provided as follows:

(1) if $n=1$, then total inventories in transportation time $=0$ (refer to Fig. 3).

(2) if $n=2$, then total inventories in transportation time $t_{3 i \pi}$ are as follows:

$$
\left(\frac{H_{i}}{2} \times \frac{t_{3 i \pi}}{2}\right)=\left(\frac{1}{2^{2}}\right) H_{i} t_{3 i \pi}
$$

(3) if $n=3$, then total inventories in transportation time $t_{3 \text { iा }}$ become

$$
\left(\frac{2 H_{i}}{3} \times \frac{t_{3 i \pi}}{3}+\frac{1 H_{i}}{3} \times \frac{t_{3 i \pi}}{3}\right)=\left(\frac{2+1}{3^{2}}\right) H_{i} t_{3 i \pi}
$$

(4) if $n=4$, then total inventories in transportation time $t_{3 i \pi}$ are as follows:

$$
\left(\frac{3 H_{i}}{4} \times \frac{t_{3 i \pi}}{4}+\frac{2 H_{i}}{4} \times \frac{t_{3 i \pi}}{4}+\frac{1 H_{i}}{4} \times \frac{t_{3 i \pi}}{4}\right)=\left(\frac{3+2+1}{4^{2}}\right) H_{i} t_{3 i \pi}
$$

Therefore, we obtain vendor's overall inventories during transportation time $t_{3 i \pi}$ are as follows (also exhibited in Eq. (10)):

$$
\left(\frac{1}{n^{2}}\right)\left(\sum_{i=1}^{n-1} i\right) H_{i} t_{3 i \pi}=\left(\frac{1}{n^{2}}\right)\left[\frac{n(n-1)}{2}\right] H_{i} t_{3 i \pi}=\left(\frac{n-1}{2 n}\right) H_{i} t_{3 i \pi}
$$

During the transportation time $t_{3 \text { iा }}$ (Fig. 3) the total inventories of product $i$ are as follows:

$$
\left(\frac{1}{n^{2}}\right)\left(\sum_{i=1}^{n-1} i\right) H_{i}\left(t_{3 i \pi}\right)=\left(\frac{1}{n^{2}}\right)\left[\frac{n(n-1)}{2}\right] H_{i}\left(t_{3 i \pi}\right)=\left(\frac{n-1}{2 n}\right) H_{i}\left(t_{3 i \pi}\right) .
$$

\section{Appendix - B}

Derivations of $T_{\min }$ (Eq. (26)) are displayed as follows. Recall Eq. (25) as follows:

$$
T_{\pi}>\sum_{i=1}^{L}\left[S_{i}+\left(\frac{\left(1-\pi_{i}\right) Q_{i}}{P_{1 i}}\right)+\left(\frac{\left(1-\pi_{i}\right) Q_{i} E\left[x_{i}\right]}{P_{2 i}}\right)\right] .
$$

Substitute $Q_{i}=\lambda_{i} T_{\pi}$ (Eq. (8)) in Eq. (B-1), one obtains below:

$$
T_{\pi}>\sum_{i=1}^{L}\left[S_{i}+\left(\frac{\left(1-\pi_{i}\right) \lambda_{i} T}{P_{1 i}}\right)+\left(\frac{\left(1-\pi_{i}\right) \lambda_{i} T E\left[x_{i}\right]}{P_{2 i}}\right)\right],
$$

or

$$
T_{\pi}\left\{1-\sum_{i=1}^{L}\left[\left(\frac{\left(1-\pi_{i}\right) \lambda_{i}}{P_{1 i}}\right)+\left(\frac{\left(1-\pi_{i}\right) \lambda_{i} E\left[x_{i}\right]}{P_{2 i}}\right)\right]\right\}>\sum_{i=1}^{L}\left(S_{i}\right) .
$$


Therefore, $T_{\pi}$ must be longer than $T_{\min }$ as shown in Eq. (26) or Eq. (B-4).

$$
T_{\pi}>\frac{\sum_{i=1}^{L}\left(S_{i}\right)}{1-\sum_{i=1}^{L}\left[\left(\frac{\left(1-\pi_{i}\right) \lambda_{i}}{P_{1 i}}\right)+\left(\frac{\left(1-\pi_{i}\right) \lambda_{i} E\left[x_{i}\right]}{P_{2 i}}\right)\right]}=T_{\min } .
$$

\section{Appendix - C}

\section{Table C-1}

Influences of variations in $\bar{\pi}$ on the distinct system expenses

\begin{tabular}{|c|c|c|c|c|c|c|c|c|c|c|c|c|c|c|}
\hline $\bar{\pi}$ & $T_{\pi}^{*}$ & $n^{*}$ & $\begin{array}{c}\text { Expected } \\
\text { system cost } \\
\text { E }\left[T C U\left(T_{\pi}^{*},\right.\right. \\
\left.\left.n^{*}\right)\right](\mathrm{A})\end{array}$ & $\begin{array}{c}\% \\
\text { change }\end{array}$ & $\begin{array}{l}\text { Rework } \\
\text { cost (B) }\end{array}$ & $\begin{array}{c}\% \\
(\mathrm{~B}) /(\mathrm{A})\end{array}$ & $\begin{array}{l}\text { Buyer's } \\
\text { holding } \\
\text { cost }(C)\end{array}$ & $\begin{array}{c}\% \\
(\mathrm{C}) /(\mathrm{A})\end{array}$ & $\begin{array}{l}\text { Transpor - } \\
\text { tation cost } \\
\text { (D) }\end{array}$ & $\begin{array}{c}\% \\
(\mathrm{D}) /(\mathrm{A})\end{array}$ & $\begin{array}{c}\text { Related } \\
\text { outsourcing } \\
\text { cost }(E)\end{array}$ & $\begin{array}{c}\% \\
(\mathrm{E}) /(\mathrm{A})\end{array}$ & $\begin{array}{l}\text { Other in- } \\
\text { house cost } \\
\text { (F) }\end{array}$ & $\begin{array}{c}\% \\
(\mathrm{~F}) /(\mathrm{A})\end{array}$ \\
\hline 0.00 & 70 & 3 & $\$ 2,191,341$ & - & & 0 & & & & $3.31 \%$ & & $0.00 \%$ & 57 & 70 \\
\hline 0.05 & 0.5619 & 3 & $\$ 2,239,383$ & $2.19 \%$ & 1,994 & $3.66 \%$ & 124,585 & $5.56 \%$ & 043 & $.22 \%$ & $\$ 141,596$ & $6.32 \%$ & 165 & $1.24 \%$ \\
\hline 0.10 & 0.5667 & 3 & $\$ 2,256,111$ & $2.96 \%$ & 7,606 & $3.44 \%$ & $\$ 124,165$ & $5.50 \%$ & $\$ 71,473$ & $3.17 \%$ & $\$ 251,780$ & $11.16 \%$ & $\$ 1,731,087$ & $76.73 \%$ \\
\hline 0.15 & 5715 & 3 & $\$ 2,272,949$ & $3.72 \%$ & 73,225 & $3.22 \%$ & $\$ 123,704$ & $5.44 \%$ & $\$ 70,921$ & $3.12 \%$ & $\$ 361,973$ & $15.93 \%$ & $\$ 1,643,127$ & $72.29 \%$ \\
\hline 0.20 & 0.5762 & 3 & $\$ 2,289,898$ & $4.50 \%$ & $\$ 68,850$ & $3.01 \%$ & $\$ 123,200$ & $5.38 \%$ & $\$ 70,387$ & $3.07 \%$ & $\$ 472,173$ & $20.62 \%$ & & $67.92 \%$ \\
\hline 0.25 & 0.5808 & 3 & $\$ 2,306,962$ & $5.28 \%$ & $\$ 64,482$ & $2.80 \%$ & & $5.32 \%$ & & $3.03 \%$ & & $25.24 \%$ & & $63.61 \%$ \\
\hline 0.30 & 0.5853 & 3 & $\$ 2,324,144$ & $6.06 \%$ & $\$ 60,122$ & $2.59 \%$ & 061 & $5.25 \%$ & $\$$ & $2.98 \%$ & & $29.80 \%$ & & $59.38 \%$ \\
\hline 0.35 & 0.5896 & 3 & $\$ 2,34$ & $6.85 \%$ & 70 & $2.38 \%$ & 21 & $5.19 \%$ & & $2.94 \%$ & & $34.29 \%$ & & $55.20 \%$ \\
\hline 0.40 & 0.5939 & 3 & $\$ 2,3$ & $7.65 \%$ & 25 & $2.18 \%$ & 734 & $5.12 \%$ & & $2.90 \%$ & & $38.71 \%$ & & $51.09 \%$ \\
\hline 0.45 & 0.5980 & 3 & $\$ 2,37$ & $8.45 \%$ & 088 & $1.98 \%$ & 997 & $5.05 \%$ & & $2.86 \%$ & & $43.06 \%$ & & $47.05 \%$ \\
\hline 0.50 & 0.6020 & 3 & $\$ 2,394,103$ & $9.25 \%$ & 760 & $1.79 \%$ & 10 & $4.98 \%$ & & $2.82 \%$ & & $47.35 \%$ & 72 & $43.06 \%$ \\
\hline 0.55 & 0.6058 & 3 & $\$ 2,411,913$ & $10.07 \%$ & $\$ 38,441$ & $1.59 \%$ & $\$ 118,372$ & $4.91 \%$ & & $2.79 \%$ & & $51.57 \%$ & & $39.14 \%$ \\
\hline 0.60 & 0.6095 & 3 & $\$ 2,429,858$ & $10.88 \%$ & $\$ 34,131$ & $1.40 \%$ & $\$ 117,481$ & $4.83 \%$ & & $2.75 \%$ & & $55.73 \%$ & & $35.28 \%$ \\
\hline 0.65 & 0.6130 & 3 & $\$ 2,447,938$ & $11.71 \%$ & $\$ 29,830$ & $1.22 \%$ & $\$ 116,537$ & $4.76 \%$ & $\$ 6$ & $2.72 \%$ & 398 & $59.82 \%$ & & $31.48 \%$ \\
\hline 0.70 & 0.6163 & 3 & $\$ 2,466,156$ & $12.54 \%$ & $\$ 25,538$ & $1.04 \%$ & $\$ 115,540$ & $4.69 \%$ & & $2.68 \%$ & 696 & $63.85 \%$ & & $27.74 \%$ \\
\hline 0.75 & 0.6194 & 3 & $\$ 2,484,515$ & $13.38 \%$ & $\$ 21,427$ & $0.86 \%$ & $\$ 114,488$ & $4.61 \%$ & & $2.65 \%$ & 004 & $67.82 \%$ & $\$ 597,922$ & $24.07 \%$ \\
\hline 0.80 & 0.6223 & 3 & $\$ 2,503,017$ & $14.22 \%$ & $\$ 21,256$ & $0.86 \%$ & $\$ 113,382$ & $4.53 \%$ & $\$ 65,564$ & $2.62 \%$ & $\$ 1,7$ & $71.73 \%$ & $\$ 511,764$ & $20.45 \%$ \\
\hline 0.85 & 0.6249 & 3 & $\$ 2,5$ & $.07 \%$ & $\$ 1$ & $0.68 \%$ & 21 & $4.45 \%$ & $\$$ & $2.59 \%$ & & $75.57 \%$ & & $16.88 \%$ \\
\hline 0.90 & 0.6274 & 3 & $\$ 2,540,456$ & $5.93 \%$ & $\$ 12,723$ & $0.50 \%$ & $\$ 111,006$ & $4.37 \%$ & $\$ 6$ & $2.56 \%$ & 993 & $79.36 \%$ & 912 & $13.38 \%$ \\
\hline 0.95 & 0.6296 & 3 & $\$ 2,55$ & $6.80 \%$ & & $0.33 \%$ & & $4.29 \%$ & & $2.53 \%$ & & $83.08 \%$ & & $9.93 \%$ \\
\hline 1.00 & 0.6315 & 3 & $\$ 2,483,483$ & $13.33 \%$ & $\$ 4,230$ & $0.17 \%$ & $\$ 108,415$ & $4.37 \%$ & $\$ 64,679$ & $2.60 \%$ & $\$ 2,236,710$ & $90.06 \%$ & $\$ 73,680$ & $2.97 \%$ \\
\hline
\end{tabular}

Table C-2

Impact of differences in $\bar{\pi}$ on production times and total machine utilization

\begin{tabular}{|c|c|c|c|c|c|c|c|}
\hline $\bar{\pi}$ & $T_{\pi} *$ & $\begin{array}{l}\text { Total utilization } \\
{[\mathrm{A}]+[\mathrm{B}]}\end{array}$ & $\begin{array}{c}\text { Sum of uptime (in } \\
\text { year) }\end{array}$ & $\begin{array}{c}\text { Utilization } \\
\text { (uptime) [A] }\end{array}$ & $\begin{array}{l}\text { Sum of rework } \\
\text { time (in year) }\end{array}$ & $\begin{array}{c}\text { Utilization (rework } \\
\text { time) }[\mathrm{B}]\end{array}$ & $\begin{array}{l}\text { Machine idle time } \\
\text { per cycle (in year) }\end{array}$ \\
\hline 0.00 & 0.5570 & 0.7193 & 0.1576 & 0.2829 & 0.2430 & 0.4363 & 0.1564 \\
\hline 0.05 & 0.5619 & 0.6833 & 0.1510 & 0.2687 & 0.2329 & 0.4145 & 0.1780 \\
\hline 0.10 & 0.5667 & 0.6474 & 0.1443 & 0.2546 & 0.2226 & 0.3928 & 0.1998 \\
\hline 0.15 & 0.5715 & 0.6114 & 0.1374 & 0.2404 & 0.2120 & 0.3710 & 0.2221 \\
\hline 0.20 & 0.5762 & 0.5754 & 0.1304 & 0.2263 & 0.2011 & 0.3490 & 0.2447 \\
\hline 0.25 & 0.5808 & 0.5394 & 0.1232 & 0.2121 & 0.1901 & 0.3273 & 0.2675 \\
\hline 0.30 & 0.5853 & 0.5035 & 0.1159 & 0.1980 & 0.1788 & 0.3055 & 0.2906 \\
\hline 0.35 & 0.5896 & 0.4676 & 0.1084 & 0.1839 & 0.1672 & 0.2836 & 0.3140 \\
\hline 0.40 & 0.5939 & 0.4316 & 0.1008 & 0.1697 & 0.1555 & 0.2618 & 0.3376 \\
\hline 0.45 & 0.5980 & 0.3955 & 0.0931 & 0.1557 & 0.1435 & 0.2400 & 0.3614 \\
\hline 0.50 & 0.6020 & 0.3596 & 0.0852 & 0.1415 & 0.1313 & 0.2181 & 0.3855 \\
\hline 0.55 & 0.6058 & 0.3237 & 0.0771 & 0.1273 & 0.1190 & 0.1964 & 0.4097 \\
\hline 0.60 & 0.6095 & 0.2878 & 0.0690 & 0.1132 & 0.1064 & 0.1746 & 0.4341 \\
\hline 0.65 & 0.6130 & 0.2517 & 0.0607 & 0.0990 & 0.0936 & 0.1527 & 0.4587 \\
\hline 0.70 & 0.6163 & 0.2158 & 0.0523 & 0.0849 & 0.0807 & 0.1309 & 0.4833 \\
\hline 0.75 & 0.6194 & 0.1799 & 0.0438 & 0.0707 & 0.0676 & 0.1091 & 0.5080 \\
\hline 0.80 & 0.6223 & 0.1438 & 0.0352 & 0.0566 & 0.0543 & 0.0873 & 0.5328 \\
\hline 0.85 & 0.6249 & 0.1079 & 0.0265 & 0.0424 & 0.0409 & 0.0655 & 0.5575 \\
\hline 0.90 & 0.6274 & 0.0719 & 0.0178 & 0.0284 & 0.0274 & 0.0437 & 0.5822 \\
\hline 0.95 & 0.6296 & 0.0359 & 0.0089 & 0.0141 & 0.0137 & 0.0218 & 0.6070 \\
\hline 1.00 & 0.6315 & 0.0000 & 0.0000 & 0.0000 & 0.0000 & 0.0000 & 0.6315 \\
\hline
\end{tabular}




\section{References}

Afshar-Nadjafi, B., \& Afshar-Nadjafi, A. (2017). A constructive heuristic for time-dependent multidepot vehicle routing problem with time-windows and heterogeneous fleet. Journal of King Saud University - Engineering Sciences, 29(1), 29-34.

Balaji, M., Velmurugan, V., Prapa, M., \& Mythily, V. (2016). A fuzzy approach for modeling and design of agile supply chains using interpretive structural modeling. Jordan Journal of Mechanical and Industrial Engineering, 10(1), 67-74.

Bolaños, R.I., Escobar, J.W., \& Echeverri, M.G. (2018). A metaheuristic algorithm for the multi-depot vehicle routing problem with heterogeneous fleet. International Journal of Industrial Engineering Computations, 9(4), 461-478.

Banerjee, A., \& Banerjee, S. (1994). A coordinated order-up-to inventory control policy for a single supplier and multiple buyers using electronic data interchange. International Journal of Production Economics, 35, 85-91.

Beladi, H., \& Mukherjee, A. (2012). Market structure and strategic bi-sourcing. Journal of Economic Behavior \& Organization, 82(1), 210-219.

Berggren, C., \& Bengtsson, L. (2004). Rethinking Outsourcing in Manufacturing: A Tale of Two Telecom Firms. European Management Journal, 22(2), 211-223.

Buckova, M., Krajcovic, M., \& Jerman, B. (2017). Impact of digital factory tools on designing of warehouses. Journal of Applied Engineering Science, 15(2), 173-180.

Cachon, G.P., \& Harker, P.T. (2002). Competition and outsourcing with scale economies. Management Science, 48(10), 1314-1333.

Chakravarty, A.K. (2017). Offshore outsourcing and ownership of facilities with productivity concerns. IISE Transactions, 49(6), 642-651.

Chiu, Y-S.P., Hsieh, Y-T., Kuo, J-S., \& Chiu, S.W. (2016a). A delayed differentiation multi-product FPR model with scrap and a multi-delivery policy-I: Using single-machine production scheme. International Journal for Engineering Modelling, 29(1-4), 37-52.

Chiu, S.W., Hsieh, Y-T., Chiu, Y-S.P., \& Hwang, M-H. (2016b). A delayed differentiation multi- product FPR model with scrap and a multi-delivery policy-II: Using two-machine production scheme. International Journal for Engineering Modelling, 29(1-4), 53-68.

Chiu, S.W., Liu, C-J., Li, Y-Y., \& Chou, C-L. (2017a). Manufacturing lot size and product distribution problem with rework, outsourcing and discontinuous inventory distribution policy. International Journal for Engineering Modelling, 30(1-4), 49-61.

Chiu, Y-S.P., Liu, C-J., \& Hwang, M-H. (2017b). Optimal batch size considering partial outsourcing plan and rework. Jordan Journal of Mechanical and Industrial Engineering, 11(3), 195-200.

Chiu, Y-S.P., Lin, H-D., Wu, M-F., \& Chiu, S.W. (2018a). Alternative fabrication scheme to study effects of rework of nonconforming products and delayed differentiation on a multiproduct supply-chain system. International Journal of Industrial Engineering Computations, 9(2), 235-248.

Çömez, N., Stecke, K.E., \& Çakanyildirim, M. (2012). Multiple in-cycle transshipments with positive delivery times. Production and Operations Management, $21(2), 378-395$.

Federgruen, A., Meissner, J., \& Tzur, M. (2007). Progressive interval heuristics for multi-item capacitated lot-sizing problems. Operations Research, 55(3), 490-502.

Fera, M., Fruggiero, F., Lambiase, A., Macchiaroli, R., \& Miranda, S. (2017). The role of uncertainty in supply chains under dynamic modeling. International Journal of Industrial Engineering Computations, 8(1), 119-140.

Fergany, H.A. (2016). Probabilistic multi-item inventory model with varying mixture shortage cost under restrictions. SpringerPlus, 5(1), art. no. 1351.

Florea Ionescu, A.I., Corboş, R-A., Popescu, R.I., \& Zamfir, A. (2016). From the factory floor to the shop floor - improved supply chain for sustainable competitive advantage with item-level RFID in retail. Economic Computation and Economic Cybernetics Studies and Research, 50(4), 119-134.

Giri, B.C., \& Roy, B. (2013). A vendor-buyer integrated production-inventory model with quantity discount and unequal sized shipments. International Journal of Operational Research, 16(1), 1-13.

Groenevelt, H., Pintelon, L., \& Seidmann, A. (1992). Production lot sizing with machine breakdowns. Management Sciences, 38, 104-123.

Grosfeld-Nir, A., \& Gerchak, Y. (2002). Multistage production to order with rework capability. 
Management Science, 48(5), 652-664.

Güder, F., \& Zydiak, J.L. (1997). Non-stationary ordering policies for multi-item inventory systems subject to a single resource constraint and quantity discounts. Computers and Operations Research, 24(1), 61-71.

Kaylani, H., Almuhtady, A., \& Atieh, A.M. (2016). Novel approach to enhance the performance of production systems using lean tools. Jordan Journal of Mechanical and Industrial Engineering, 10(3), 215-229.

Kohli, R., \& Park, H. (1994). Coordinating buyer-seller transactions across multiple products. Management Science, 40(9), 45-50.

Korgaonker, M.G. (1979). Integrated production inventory policies for multistage multiproduct batch production systems. Journal of the Operational Research Society, 30(4), 355-362.

Lee, D-H., Lim, S-K., Lee, G-C., Jun, H-B., \& Kim, Y-D. (1997). Multi-period part selection and loading problems in flexible manufacturing systems. Computers \& Industrial Engineering, 33(3-4), 541-544.

Mendelson, H., \& Parlaktürk, A.K. (2008). Product-line competition: Customization vs. proliferation. Management Science, 54(12), 2039-2053.

Mokhtari, H., \& Abadi, I.N.K. (2013). Scheduling with an outsourcing option on both manufacturer and subcontractors. Computers \& Operations Research, 40(5), 1234-1242.

Nahmias, S. (2009). Production \& Operations Analysis. McGraw-Hill Inc. New York.

Nourelfath, M. (2011). Service level robustness in stochastic production planning under random machine breakdowns. European Journal of Operational Research, 212(1), 81-88.

Raj, V., \& Prabha, G. (2016). Synthesis, characterization and in vitro drug release of cisplatin loaded Cassava starch acetate-PEG/gelatin nanocomposites. Journal of the Association of Arab Universities for Basic and Applied Sciences, 21, 10-16.

Rardin, R.L. (1998). Optimization in Operations Research. Prentice-Hall, New Jersey.

Razmi, J., Kazerooni, M.P., \& Sangari, M.S. (2016). Designing an integrated multi-echelon, multiproduct and multi-period supply chain network with seasonal raw materials. Economic Computation and Economic Cybernetics Studies and Research, 50(1), 273-290.

Regti, A., El Kassimi, A., Laamari, M.R., \& El Haddad, M. (2017). Competitive adsorption and optimization of binary mixture of textile dyes: A factorial design analysis. Journal of the Association of Arab Universities for Basic and Applied Sciences, 24, 1-9.

Rodado, D.N., Escobar, J.W., García-Cáceres, R.G., \& Niebles Atencio, F.A. (2017). A mathematical model for the product mixing and lot-sizing problem by considering stochastic demand. International Journal of Industrial Engineering Computations, 8(2), 237-250.

Saari, J., \& Odelius, J. (2018). Detecting operation regimes using unsupervised clustering with infected group labelling to improve machine diagnostics and prognostics. Operations Research Perspectives, $5,232-244$.

Settanni, E., Harrington, T.S., \& Srai, J.S. (2017). Pharmaceutical supply chain models: A synthesis from a systems view of operations research. Operations Research Perspectives, 4, 74-95.

Sultana, B., \& Mustafa, M.W. (2017). Distribution system loss minimization with network reconfiguration and cost-benefit price based demand reduction modeling. Journal of Engineering Research, 5(1), 140-162.

Sucky, E. (2004). Coordinated order and production policies in supply chains. OR Spectrum, 26(4), 493520.

Tamura, T. (1988) Solution procedure for the multi-item and multi-stage production planning problem. Transactions of the Japan Society of Mechanical Engineers, Part C, 54(504), 1974-1982.

Taleizadeh, A.A., Jalali-Naini, S.G., Wee, H-M., \& Kuo, T-C. (2013). An imperfect multi-product production system with rework. Scientia Iranica 20(3), 811-823.

Thomas D.J., \& Hackman S.T. (2003). A committed delivery strategy with fixed frequency and quantity. European Journal of Operational Research, 148(2), 363-373.

Ueno, N., Okuhara, K., Ishii, H., Shibuki, H., \& Kuramoto, T. (2007). Multi-item production planning and management system based on unfulfilled order rate in supply chain. Journal of the Operations Research Society of Japan, 50(3), 201-218.

Vishwakarma, A., Kumar, A., \& Singh, G.K. (2017). Design of near-perfect-reconstructed transmultiplexer using different modulation techniques: A comparative study. Journal of King Saud 
University - Engineering Sciences, 29(3), 257-263.

Vujosevic, M., Makajic-Nikolic, D., \& Pavlovic, P. (2017). A new approach to determination of the most critical multi-state components in multi-state systems. Journal of Applied Engineering Science, 15(4), 401-405.

Zahedi, Z., Ari Samadhi, T.M.A., Suprayogi, S., \& Halim, A.H. (2016). Integrated batch production and maintenance scheduling for multiple items processed on a deteriorating machine to minimize total production and maintenance costs with due date constraint. International Journal of Industrial Engineering Computations, 7(2), 229-244.

Zahorik, A., Thomas, L.J., \& Trigeiro, W.W. (1984). Network Programming Models for Production Scheduling in Multi-stage, Multi-item Capacitated Systems. Management Science, 30(3), 308-325.

Zipkin, P.H. (1995). Performance analysis of a multi-item production-inventory system under alternative policies. Management Science, 41(4), 690-703.

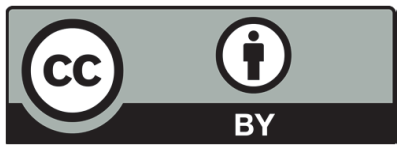

C 2019 by the authors; licensee Growing Science, Canada. This is an open access article distributed under the terms and conditions of the Creative Commons Attribution (CCBY) license (http://creativecommons.org/licenses/by/4.0/). 